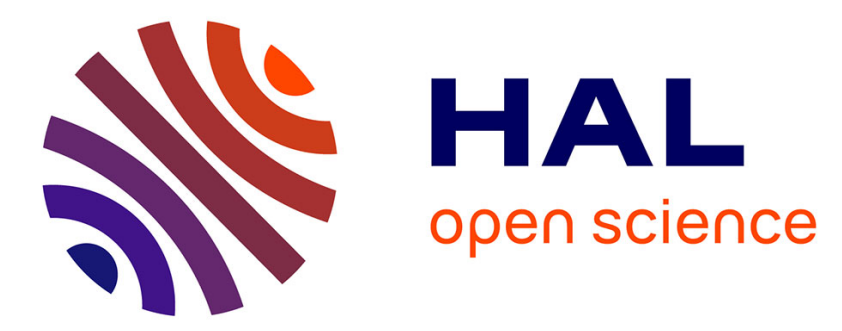

\title{
Magnetic and structural properties of iron-based oxide glasses, Fe 2O3-BaO-B2O3, from 57Fe Mössbauer spectroscopy
}

A. Bonnenfant, J.M. Friedt, M. Maurer, J.P. Sanchez

\section{To cite this version:}

A. Bonnenfant, J.M. Friedt, M. Maurer, J.P. Sanchez. Magnetic and structural properties of ironbased oxide glasses, Fe 2O3-BaO-B2O3, from 57Fe Mössbauer spectroscopy. Journal de Physique, 1982, 43 (10), pp.1475-1487. 10.1051/jphys:0198200430100147500 . jpa-00209529

HAL Id: jpa-00209529

https://hal.science/jpa-00209529

Submitted on 1 Jan 1982

HAL is a multi-disciplinary open access archive for the deposit and dissemination of scientific research documents, whether they are published or not. The documents may come from teaching and research institutions in France or abroad, or from public or private research centers.
L'archive ouverte pluridisciplinaire HAL, est destinée au dépôt et à la diffusion de documents scientifiques de niveau recherche, publiés ou non, émanant des établissements d'enseignement et de recherche français ou étrangers, des laboratoires publics ou privés. 
Classification

Physics Abstracts

$61.40 \mathrm{D}-75.50 \mathrm{~K}-76.80$

\title{
Magnetic and structural properties of iron-based oxide glasses, $\mathrm{Fe}_{2} \mathrm{O}_{3}-\mathrm{BaO}-\mathrm{B}_{2} \mathrm{O}_{3}$, from ${ }^{57} \mathrm{Fe}$ Mössbauer spectroscopy
}

\author{
A. Bonnenfant, J. M. Friedt, M. Maurer and J. P. Sanchez \\ Centre de Recherches Nucléaires, 67037 Strasbourg Cedex, France
}

(Reçu le 28 janvier 1982, révisé le 6 mai, accepté le 7 juin 1982)

\begin{abstract}
Résumé. - La configuration électronique du fer, l'ordre structural à courte distance et les propriétés magnétiques de verres de composition $\left(\mathrm{Fe}_{2} \mathrm{O}_{3}\right)_{x}(\mathrm{BaO})_{y}\left(\mathrm{~B}_{2} \mathrm{O}_{3}\right)_{z}$ sont établis par spectroscopie Mössbauer de ${ }^{57} \mathrm{Fe}$ en combinaison avec des mesures macroscopiques. La coordinance moyenne du fer est déterminée par le rapport atomique $\mathrm{Fe} / \mathrm{O}$ dans le milieu tandis que la configuration de valence du fer dépend principalement des conditions de préparation. Un ordre structural à courte distance très strict est mis en évidence autour des atomes de $\mathrm{Fe}$; il correspond à des fluctuations aléatoires des angles et longueurs de liaison $\mathrm{Fe}-\mathrm{O}$. A faible concentration en $\mathrm{Fe}_{2} \mathrm{O}_{3}$, le verre reste paramagnétique jusqu'à $1,5 \mathrm{~K}$; la mesure locale de moment révèle cependant la coexistence d'ions isolés et d'agrégats à l'échelle atomique. A concentration moyenne en $\mathrm{Fe}_{2} \mathrm{O}_{3}(\sim 25 \%)$, le verre présente une transition mictomagnétique. A concentration élevée en $\mathrm{Fe}_{2} \mathrm{O}_{3}(\sim 50 \%)$, le verre présente un comportement quasi-superparamagnétique, révélant une inhomogénéité de la répartition du fer dans le milieu. Les phases formées lors de la cristallisation du verre à concentration moyenne en $\mathrm{Fe}_{2} \mathrm{O}_{3}$ sont identifiées par spectroscopie Mössbauer.
\end{abstract}

\begin{abstract}
Fe}$ Mössbauer spectroscopy has been combined with bulk results to determine the electronic configuration of iron, the short-range structural order and the magnetic properties of glasses in the system $\left(\mathrm{Fe}_{2} \mathrm{O}_{3}\right)_{x}(\mathrm{BaO})_{y}\left(\mathrm{~B}_{2} \mathrm{O}_{3}\right)_{z}$. The average coordination of the iron atoms is determined by the $\mathrm{Fe} / \mathrm{O}$ atomic ratio while the valence state of $\mathrm{Fe}$ seems to be affected essentially by the preparation conditions. Structural short-range order around $\mathrm{Fe}$ atoms is concluded to be very strong, with random bonding angle and distance fluctuations. At low $\mathrm{Fe}_{2} \mathrm{O}_{3}$ content, the glass is paramagnetic down to $1.5 \mathrm{~K}$. Local moment measurements reveal the coexistence of isolated $\mathrm{Fe}$ ions and of atomic scale clusters. At intermediate $\mathrm{Fe}_{2} \mathrm{O}_{3}$ concentration $(\sim 25 \%)$, the glass presents a mictomagnetic transition. At large $\mathrm{Fe}_{2} \mathrm{O}_{3}$ content $(\sim 50 \%)$, the glass behaves like a superparamagnet, indicating inhomogeneous distribution of the $\mathrm{Fe}$ atoms in the solid. Mössbauer spectroscopy is also applied to the investigation of the crystallization of a glass with intermediate $\mathrm{Fe}_{2} \mathrm{O}_{3}$ concentration.
\end{abstract}

1. Introduction. - The investigation of the structural and magnetic properties specific to amorphous systems is of much current interest [1-3]. The understanding of these properties in insulating compounds differs from that in metallic glasses owing to dominant superexchange interactions. Therefore, the magnetic properties of amorphous insulators will reflect rather directly the distributions of bonding angles and distances. The atomic structure is best approximated by a random coordination model with preferred cation-anion bonds in a manner which ensures local charge neutrality $[1,4]$. It would be expected that these features should permit an easier theoretical approach of amorphous insulators as compared with metals. Moreover, there are only few amorphous materials which display negative exchange interactions leading to an ordered state with random spin freezing (speromagnetism) [5].
Considerable work has indeed been devoted recently to amorphous insulators [1-8]. Simple ionic compounds are generally difficult to obtain in the amorphous state $[9,10]$. Extensive literature exists on binary or ternary oxides, which are easier to prepare but usually cannot be compared to corresponding crystalline systems. Current interest in amorphous oxide glasses primarily concerns the following aspects :

a) The electronic structure and bonding properties of the cations present in the glass. In the case of the widely investigated iron glasses, this corresponds more precisely to the determination of the valence state and the coordination of the $\mathrm{Fe}$ ions, in connection with the glass former or glass modifier behaviour $[11,12]$. These problems have been extensively studied in many systems, in particular by spectroscopic methods, e.g., Mössbauer, NMR, ESR, etc... In the 
$\mathrm{Fe}_{2} \mathrm{O}_{3}-\mathrm{BaO}-\mathrm{B}_{2} \mathrm{O}_{3}$ glasses considered here, general trends emerging from previous studies indicate that the coordination of the $\mathrm{Fe}^{3+}$ ions is governed by the $\mathrm{Fe}_{2} \mathrm{O}_{3} / \mathrm{BaO}$ ratio (i.e., tetrahedral network when $\mathrm{Fe}_{2} \mathrm{O}_{3} / \mathrm{BaO}<1$ and both tetrahedral and octahedral coordination when $\mathrm{Fe}_{2} \mathrm{O}_{3} / \mathrm{BaO}>1$ ) [13]. For comparison, ${ }^{11} \mathrm{~B}$ NMR in alkali-boron oxide glasses demonstrates that tetrahedral coordination of boron is preferred to the 3-coordinate oxygen neighbourhood when the proportion (up to $33 \%$ ) of alkali oxide increases, i.e. for increasing $\mathrm{O} / \mathrm{B}$ atomic ratio [14]. Thus, the metal-oxygen coordination number is governed by the atomic ratio of the elements present in the glass. The presence of $\mathrm{Fe}^{2+}$ ions in some glasses is related to the conditions of preparation.

b) The peculiar magnetic transitions and orderings occurring in such glasses are a consequence of frustration connected with topological disorder [5-10]. Speromagnetism has been demonstrated in a few insulating amorphous materials and mictomagnetism or spin glass transitions have been characterized in a variety of concentrated oxide glasses $[5-7,15,16]$.

c) Additional problems of interest concern the possibility of chemical short-range order and compositional heterogeneities [17]. In oxide glasses of composition $(1-x)\left[0.2 \mathrm{BaO}-0.8 \mathrm{~B}_{2} \mathrm{O}_{3}\right] x \mathrm{Fe}_{2} \mathrm{O}_{3}$ the occurrence of small iron clusters (dimers, trimers, etc...) has been claimed at low $\mathrm{Fe}$ concentration [18], while superparamagnetic behaviour has been demonstrated at high Fe content.

d) The crystallization mechanisms, the phase analysis and the evolution of the magnetic properties on crystallization is of intrinsic interest as well as from the point of view of applications. For example, microcrystalline (possibly monodomain) precipitates of barium hexaferrite evolve within a non-magnetic host ; such systems may be considered for permanent magnet applications $[19,20]$.

2. Experimental. - The amorphous samples were prepared by quenching from the melt between rollers as described previously [19]. The final composition was checked by chemical analysis. The non-crystalline nature of the materials was established by X-ray and electron diffraction halos as well as from crystallization on thermal annealing as investigated by DTA and X-ray analyses. The evolution of the bulk magnetic properties on crystallization has been reported separately $[19,20]$.

The ${ }^{57} \mathrm{Fe}$ Mössbauer experiments were performed as a function of temperature between 1.5 and $800 \mathrm{~K}$ using a ${ }^{57} \mathrm{Co} / \mathrm{Rh}$ source. Some experiments were performed at temperatures between 4.2 and $300 \mathrm{~K}$ in a longitudinal magnetic field up to $100 \mathrm{kOe}$. Thin absorbers $\left(2-5 \mathrm{mg} \mathrm{Fe} / \mathrm{cm}^{2}\right)$ were used for measurements in order to minimize intensity saturation effects [21]. The data were computer analysed for the hyperfine interaction parameters and their possible distributions ; in the case of non-collinear quadrupole and magnetic interactions, the calculation of the spectral shape is performed numerically by diagonalization of the full nuclear Hamiltonians rather than using perturbation calculations. A comprehensive discussion of the method of analysis is developed in the text.

3. Experimental results on the amorphous samples. - ${ }^{57} \mathrm{Fe}$ Mössbauer measurements are reported for amorphous ternary oxides of nominal molar compositions :

$$
\begin{array}{ll}
\left(\mathrm{Fe}_{2} \mathrm{O}_{3}\right)_{30}(\mathrm{BaO})_{45}\left(\mathrm{~B}_{2} \mathrm{O}_{3}\right)_{25} & \text { sample A } \\
\left(\mathrm{Fe}_{2} \mathrm{O}_{3}\right)_{30}(\mathrm{BaO})_{17.5}\left(\mathrm{~B}_{2} \mathrm{O}_{3}\right)_{52.5} & \text { sample B } \\
\left(\mathrm{Fe}_{2} \mathrm{O}_{3}\right)_{50}(\mathrm{BaO})_{35}\left(\mathrm{~B}_{2} \mathrm{O}_{3}\right)_{15} & \text { sample C } \\
\left(\mathrm{Fe}_{2} \mathrm{O}_{3}\right)_{5}(\mathrm{BaO})_{24}\left(\mathrm{~B}_{2} \mathrm{O}_{3}\right)_{71} & \text { sample D . }
\end{array}
$$

They are discussed in combination with previously published $[19,20]$ static magnetization and susceptibility results. In addition, dynamic susceptibility measurements were performed on sample A (the only one presenting a unique valence state and coordination of the $\mathrm{Fe}$ cations) in which the magnetic transition and the nature of the ordered state are investigated in detail [22].

The Mössbauer spectra of sample A reveal a broadened quadrupole doublet in the temperature range from 670 to $42 \mathrm{~K}$ (Fig. 1). The isomer shift characterizes $\mathrm{Fe}^{3+}$ ion in tetrahedral environment. The average quadrupole splitting $\left(\Delta_{\mathrm{L}}\right)$, isomer shift $\left(\delta_{\text {IS }}\right)$

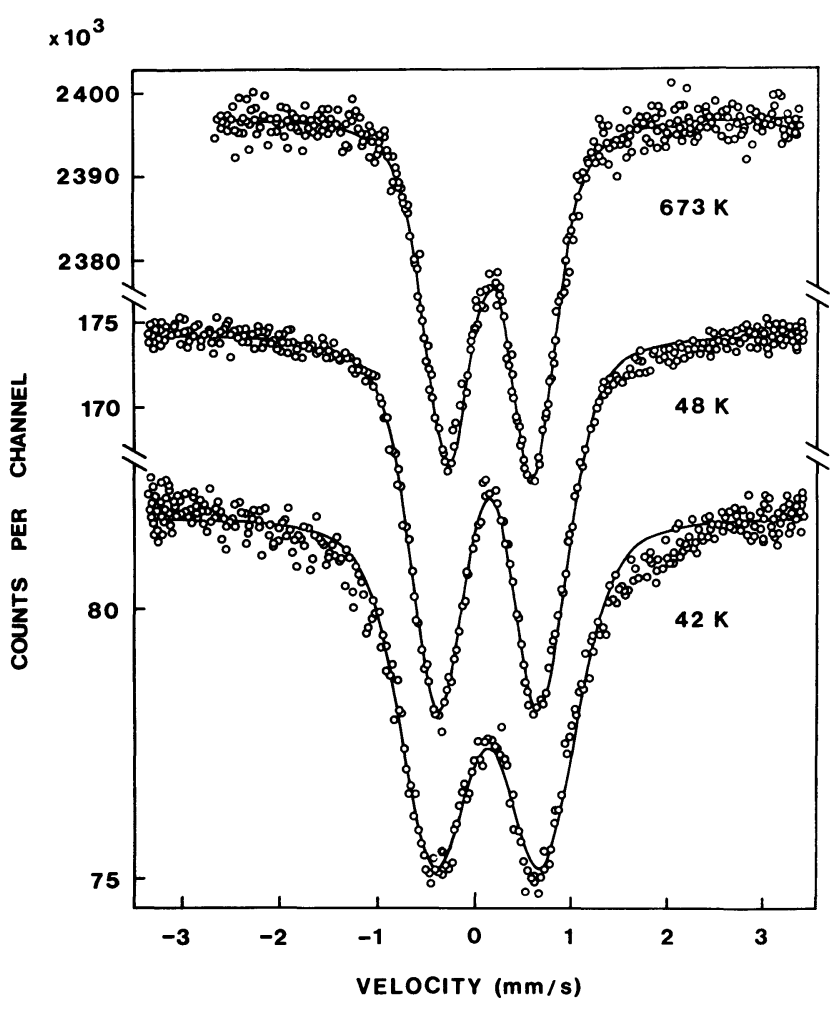

Fig. 1. - Mössbauer spectra in the paramagnetic phase of sample $A\left(\mathrm{Fe}_{2} \mathrm{O}_{3}\right)_{30}(\mathrm{BaO})_{45}\left(\mathrm{~B}_{2} \mathrm{O}_{3}\right)_{25}$. The full line corresponds to a fit with a Gaussian distribution of $\Delta$. 
and resonance width $\left(W_{\mathrm{L}}\right)$ deduced under the assumption of two Lorentzian lines are summarized in table I. The linewidths are found to be equal for both components and are comparable to those reported previously in other oxide glasses [11-13, 15]. The spectra broaden sharply below $42 \mathrm{~K}$, presenting complex shapes between 42 and $29 \mathrm{~K}$ (Fig. 2). Below $29 \mathrm{~K}$, resolved magne-

Table I. - Isomer shifts $\left(\delta_{\mathrm{IS}}\right)$, quadrupole splitting $\left(\Delta_{\mathrm{L}}\right)$, resonance width $\left(W_{\mathrm{L}}\right)$ assuming Lorentzian lineshapes.

Mean value $(\bar{\Delta})$ and deviation $(\sigma)$ assuming Gaussian distribution of quadrupole splitting

$$
\left[P(\Delta) \propto 1 / \sigma \exp -((\Delta-\bar{\Delta}) / 2 \sigma)^{2}\right]
$$

in the paramagnetic spectra of the glass $\left(\mathrm{Fe}_{2} \mathrm{O}_{3}\right)_{30^{-}}$ $(\mathrm{BaO})_{45}\left(\mathrm{~B}_{2} \mathrm{O}_{3}\right)_{25}$ (sample $\left.\mathrm{A}\right)$. The isomer shift refers to Fe metal at $300 \mathrm{~K}$.

\begin{tabular}{|c|c|c|c||c|c|}
\hline$T(K)$ & $\begin{array}{c}\delta_{I S}(\mathrm{~mm} / \mathrm{s}) \\
\pm 0.02\end{array}$ & $\begin{array}{c}\mathcal{L}_{\mathrm{L}}(\mathrm{mm} / \mathrm{s}) \\
\pm 0.02\end{array}$ & $\begin{array}{c}W_{\mathrm{L}}(\mathrm{mm} / \mathrm{s}) \\
\pm 0.02\end{array}$ & $\begin{array}{c}\bar{\Delta}_{(\mathrm{mm} / \mathrm{s})} \\
\pm 0.02\end{array}$ & $\begin{array}{c}\sigma \\
\pm 0.01\end{array}$ \\
\hline 673 & 0.02 & 0.89 & 0.53 & 0.88 & 0.24 \\
300 & 0.25 & 1.01 & 0.60 & 1.00 & 0.29 \\
49 & 0.38 & 1.05 & 0.61 & 1.05 & 0.30 \\
44 & 0.38 & 1.08 & 0.77 & 1.10 & 0.40 \\
\hline
\end{tabular}

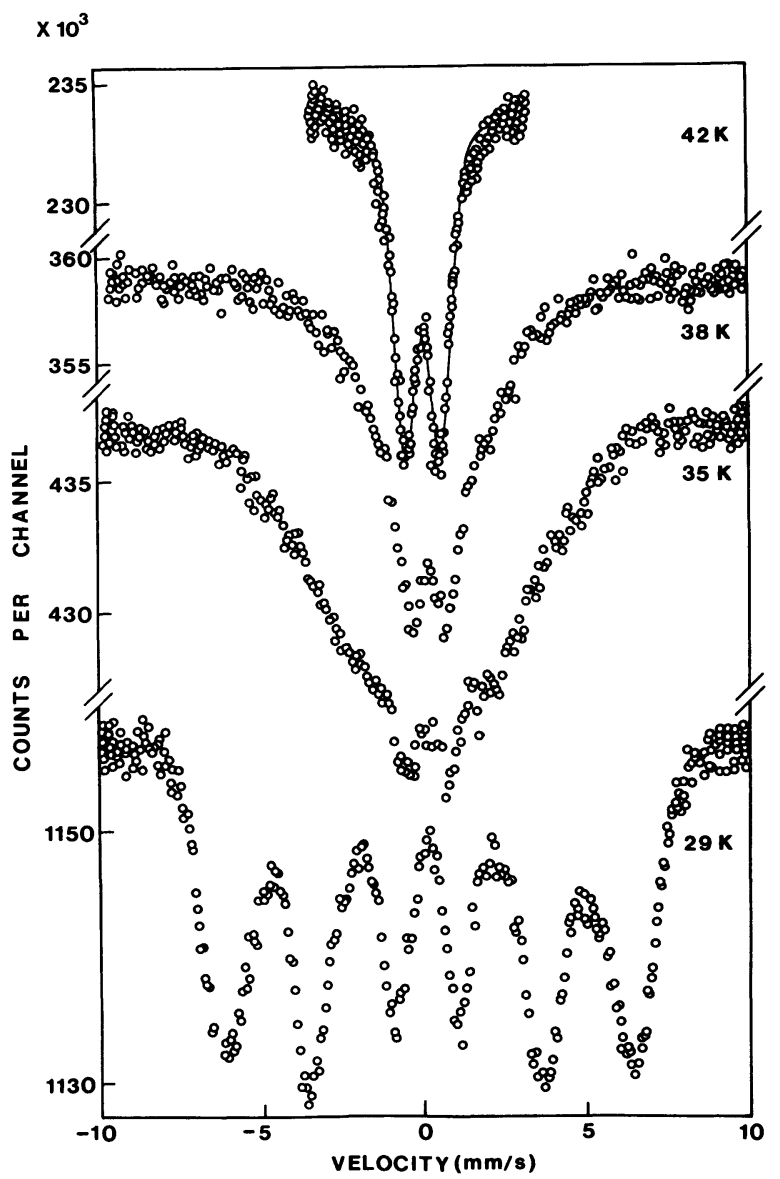

Fig. 2. - Temperature dependence of the spectra of sample A in the vicinity of the magnetic transition. tic hyperfine spectra are observed (Fig. 3). For the orientation of the data analysis it is of interest to note that the magnetic spectra appear symmetrical, in apparent contradiction with the quadrupolar splitting at higher temperature. Assuming Lorentzian lineshapes for the individual spectral components, the analysis of the $4.2 \mathrm{~K}$ data provides linewidths for the inner, middle and outer lines of $0.75,1.08$ and $1.50 \mathrm{~mm} / \mathrm{s}$ while the relative areas are almost in the theoretical ratio of $1: 2: 3$ for a thin sample $\left(2 \mathrm{mg} \mathrm{Fe} / \mathrm{cm}^{2}\right)$. Proper analysis of the distribution of hyperfine parameters from these data is discussed below (section 4).

Magnetization curves for this sample (A) are linear down to $4.2 \mathrm{~K}$ in fields up to $50 \mathrm{kOe}$ except in the low field region ( $<5 \mathrm{kOe})$ where a very weak ferromagnetic component appears [19, 20, 23]. The latter behaviour probably arises from a minor contaminant of ferrimagnetic $\mathrm{BaFe}_{12} \mathrm{O}_{19}$ which is undetected by X-ray, electron diffraction and Mössbauer analyses. Recent high field magnetization $(\leqslant 150 \mathrm{kOe})$ measurements confirm linearity above $80 \mathrm{~K}$ and reveal slight curvature below this temperature [24]. It should be noticed that the high field magnetization amounts to only a few percents of the calculated saturation value. The susceptibility deduced from the slope of the linear part of the magnetization curves follows a Curie-Weiss law above $80 \mathrm{~K}$ with $C=1.52$ and $\theta_{\mathrm{p}}=-95 \mathrm{~K}$. The molar Curie-Weiss constant $C$ is significantly below the value $(4.38)$ predicted for

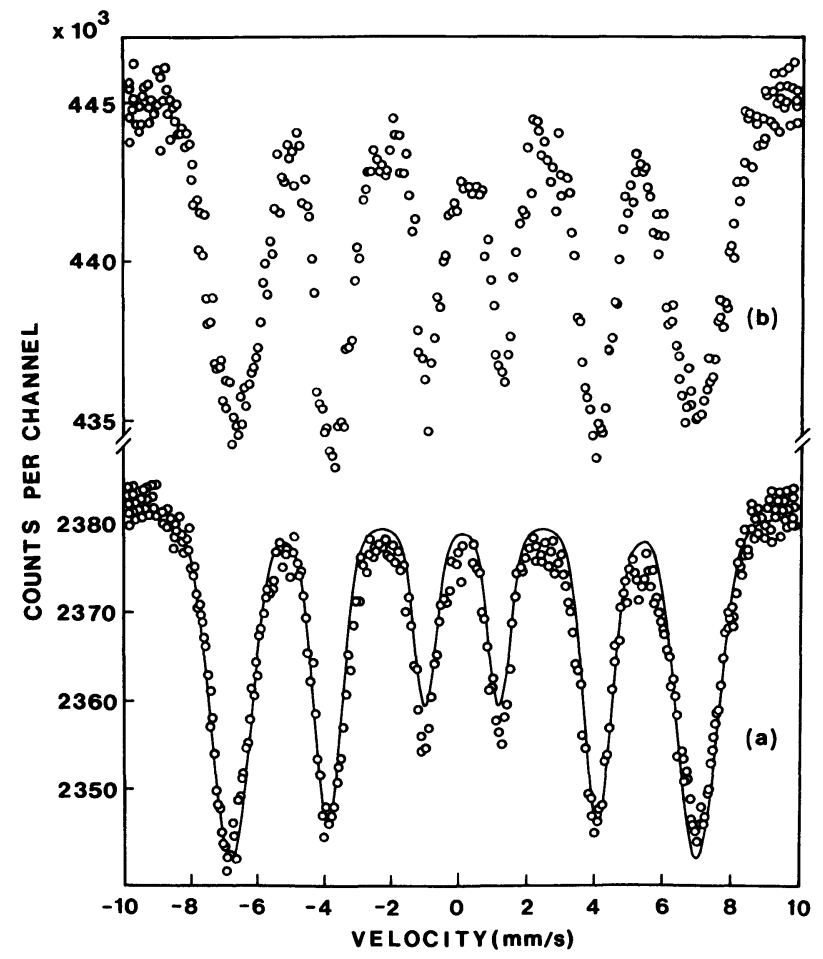

Fig. 3. - Mössbauer spectra of sample A at $4.2 \mathrm{~K}$. (a) In the absence of external field ; the full line corresponds to a fit as discussed in the text (with equal weights of + and - signs of the $\Delta$ distributions). (b) In the presence of an external field of $45 \mathrm{kOe}$. 
free $\mathrm{Fe}^{3+}$ ions; the negative paramagnetic Curie temperature $\theta_{\mathrm{p}}$ and magnetization indicate predominant antiferromagnetic exchange interactions. Below $80 \mathrm{~K}$ the reciprocal susceptibility $v s$. $T$ curve deviates from linearity and reaches a minimum at $12 \mathrm{~K}$ [19]. The increase in susceptibility below $80 \mathrm{~K}$ may be due to large magnetic moments localized in small clusters [8]. Thermoremanent effects are observed below $14 \mathrm{~K}$ for a sample cooled in a field of $18.8 \mathrm{kOe}$ $[19,23]$. Unidirectional remanence and displaced hysteresis loops observed at $4.2 \mathrm{~K}$ are comparable to those reported for metallic mictomagnets [25]. In order to elucidate the discrepancy between the appearance of magnetic hyperfine interactions in Mössbauer spectroscopy at $42 \mathrm{~K}$ and the unusual temperature dependence of susceptibility (suggesting a transition temperature of $12 \mathrm{~K}$ ), dynamic susceptibility measurements were performed in a low field of $6 \mathrm{Oe}$ at a frequency of $70 \mathrm{~Hz}$ [22]. They reveal a cusp characteristic of a mictomagnetic transition at a temperature of $38 \mathrm{~K}$.

Sample $\mathbf{B}$ of nominal molar composition $\left(\mathrm{Fe}_{2} \mathrm{O}_{3}\right)_{30}(\mathrm{BaO})_{17.5}\left(\mathrm{~B}_{2} \mathrm{O}_{3}\right)_{52.5}$ (i.e. increasing the $\mathrm{B}_{2} \mathrm{O}_{3} / \mathrm{BaO}$ ratio at constant $\mathrm{Fe}_{2} \mathrm{O}_{3}$ content vs. sample A) presents three Mössbauer resonance lines above $24 \mathrm{~K}$ (Fig. 4). The deconvolution of these spectra into two broadened quadrupole doublets characterizes the simultaneous presence of $\mathrm{Fe}^{3+}(\sim 76 \%)$ and $\mathrm{Fe}^{2+}(\sim 24 \%)$ ions (Table II). The onset of magnetic hyperfine splitting occurs at $22 \pm 1 \mathrm{~K}$, resulting at $4.2 \mathrm{~K}$ in a broadened magnetic pattern

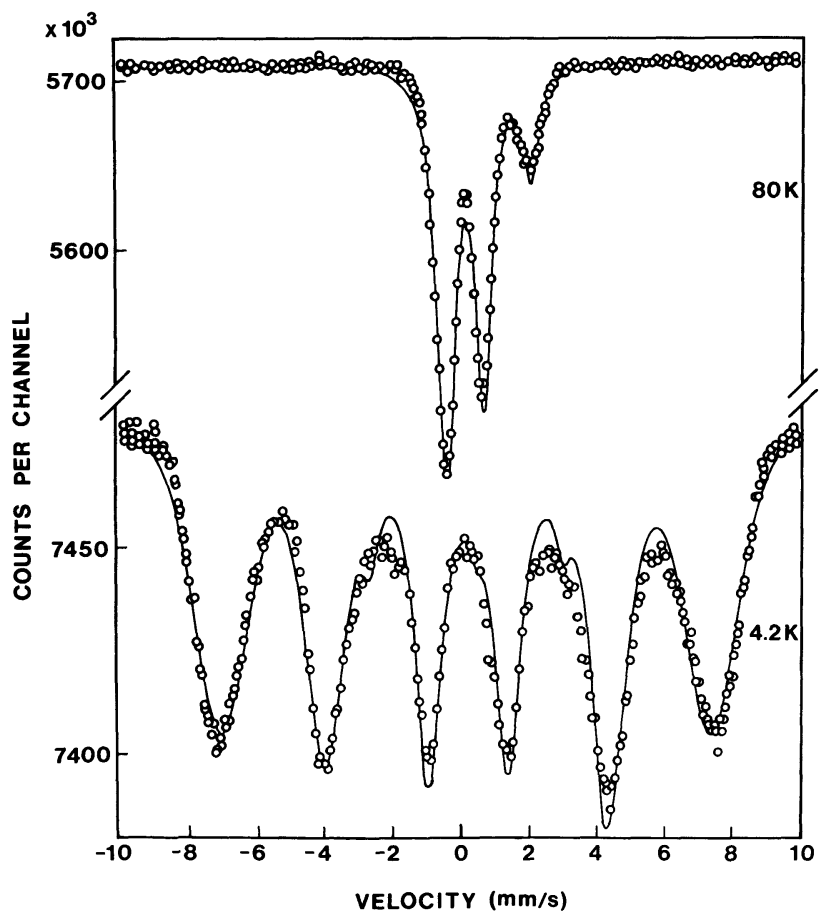

Fig. 4. - Mössbauer spectra of sample $B$ $\left(\mathrm{Fe}_{2} \mathrm{O}_{3}\right)_{30}(\mathrm{BaO})_{17.5}\left(\mathrm{~B}_{2} \mathrm{O}_{3}\right)_{52.5}$ in the paramagnetic and ordered phases.
Table II. - Hyperfine data from the analysis of the ${ }^{57} \mathrm{Fe}$ Mössbauer spectra of the glass $\left(\mathrm{Fe}_{2} \mathrm{O}_{3}\right)_{30^{-}}$ $(\mathrm{BaO})_{17.5}\left(\mathrm{~B}_{2} \mathrm{O}_{3}\right)_{52.5}$ (sample $\left.\mathrm{B}\right)$. $\bar{H}_{\mathrm{hf}}$ and $\sigma$ are respectively the mean value and the deviation of the Gaussian distribution of the hyperfine field. Other symbols are defined as in table $I$.

\begin{tabular}{|l|c|c|c|c|c|c|}
\hline$T(\mathrm{~K})$ & & $\begin{array}{c}\delta_{\mathrm{IS}}(\mathrm{mm} / \mathrm{s}) \\
\pm 0.02\end{array}$ & $\begin{array}{c}\Delta_{\mathrm{L}}(\mathrm{mm} / \mathrm{s}) \\
\pm 0.02\end{array}$ & $\begin{array}{c}\mathrm{W}(\mathrm{mm} / \mathrm{s}) \\
\pm 0.02\end{array}$ & $\begin{array}{c}\overline{\mathrm{H}}_{\mathrm{hf}}(\mathrm{kOe}) \\
\pm 5\end{array}$ & $\begin{array}{c}\sigma \\
\pm 1\end{array}$ \\
\hline 80 & $\mathrm{Fe}^{3+}$ & 0.32 & 1.05 & 0.56 & - & - \\
$\mathrm{Fe}^{2+}$ & 0.92 & 2.68 & 0.56 & - & - \\
\hline 4.2 & $\mathrm{Fe}^{3+}$ & 0.42 & $0^{*}$ & $0.91^{*}$ & 454 & 25 \\
& $\mathrm{Fe}^{2+}$ & 1.11 & 2.7 & 0.60 & $217^{* *}$ & - \\
\hline
\end{tabular}

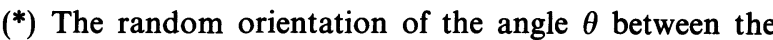
$E F G$ and $H_{\mathrm{hf}}$ axes has been taken into account by introducing an uniform broadening of the lines and setting $\Delta=0$ (see text, Eq. (2)).

$(* *) \theta=80^{\circ}$ (see text).

which can be resolved into two magnetic sextets (Fig. 4). Because of the coexistence of two valence states of iron, bulk magnetic measurements have not been carried out in detail on this sample.

Sample $\mathrm{C},\left(\mathrm{Fe}_{2} \mathrm{O}_{3}\right)_{50}(\mathrm{BaO})_{35}\left(\mathrm{~B}_{2} \mathrm{O}_{3}\right)_{15}$, presents at high temperature $(200 \mathrm{~K}<T<300 \mathrm{~K})$ a broadened and asymmetric doublet (Fig. 5). A magnetic spectrum, coexisting with the doublet, progressively develops below $200 \mathrm{~K}$; the paramagnetic component vanishes below $55 \mathrm{~K}$ (Fig. 5). Using Lorentzian lineshapes, the paramagnetic spectra were analysed as a superposition of two symmetrical doublets with different isomer shifts and quadrupole splittings (Table III). The magnetic spectra are represented as a superposition of two sextets with different isomer shifts and hyperfine fields together with vanishing quadrupole effects (see discussion below). Both the $\delta_{\mathrm{Is}}$ and $H_{\mathrm{hf}}$ values of these two sites characterize the coexistence of tetrahedral and octahedral coordination of $\mathrm{Fe}^{3+}$ ions.

Table III. - Hyperfine data from the analysis of the ${ }^{57} \mathrm{Fe}$ Mössbauer spectra of the glass $\left(\mathrm{Fe}_{2} \mathrm{O}_{3}\right)_{50^{-}}$ $(\mathrm{BaO})_{35}\left(\mathrm{~B}_{2} \mathrm{O}_{3}\right)_{15}$, sample C. Approximately $51 \%$ of the $\mathrm{Fe}^{3+}$ are octahedrically coordinated whereas $49 \%$ of the ions are in tetrahedral coordination.

\begin{tabular}{|c|c|c|c|c|c|c|}
\hline$T(\mathrm{~K})$ & & $\begin{array}{c}\delta_{\mathrm{IS}}(\mathrm{mm} / \mathrm{s}) \\
\pm 0.02\end{array}$ & $\begin{array}{c}\Delta_{\mathrm{L}}(\mathrm{mm} / \mathrm{s}) \\
\pm 0.02\end{array}$ & $\begin{array}{c}\mathrm{W}(\mathrm{mm} / \mathrm{s}) \\
\pm 0.02\end{array}$ & $\begin{array}{c}\overline{\mathrm{F}}_{\mathrm{hf}}(\mathrm{kOOe}) \\
\pm 5\end{array}$ & $\begin{array}{c}\sigma \\
\pm 0.05\end{array}$ \\
\hline 250 & $\begin{array}{c}\mathrm{Fe}^{3+}\left(\mathrm{T}_{\mathrm{d}}\right) \\
\mathrm{Fe}^{3+}\left(O_{\mathrm{h}}\right)\end{array}$ & 0.21 & 0.90 & 0.52 & - & - \\
4.2 & $\begin{array}{l}0.44 \\
\mathrm{Fe}^{3+}\left(\mathrm{T}_{\mathrm{d}}\right) \\
\mathrm{Fe}^{3+}\left(O_{\mathrm{h}}\right)\end{array}$ & 0.37 & 0.82 & 0.52 & - & - \\
\hline
\end{tabular}

(*) See table II and text, equation (2). 


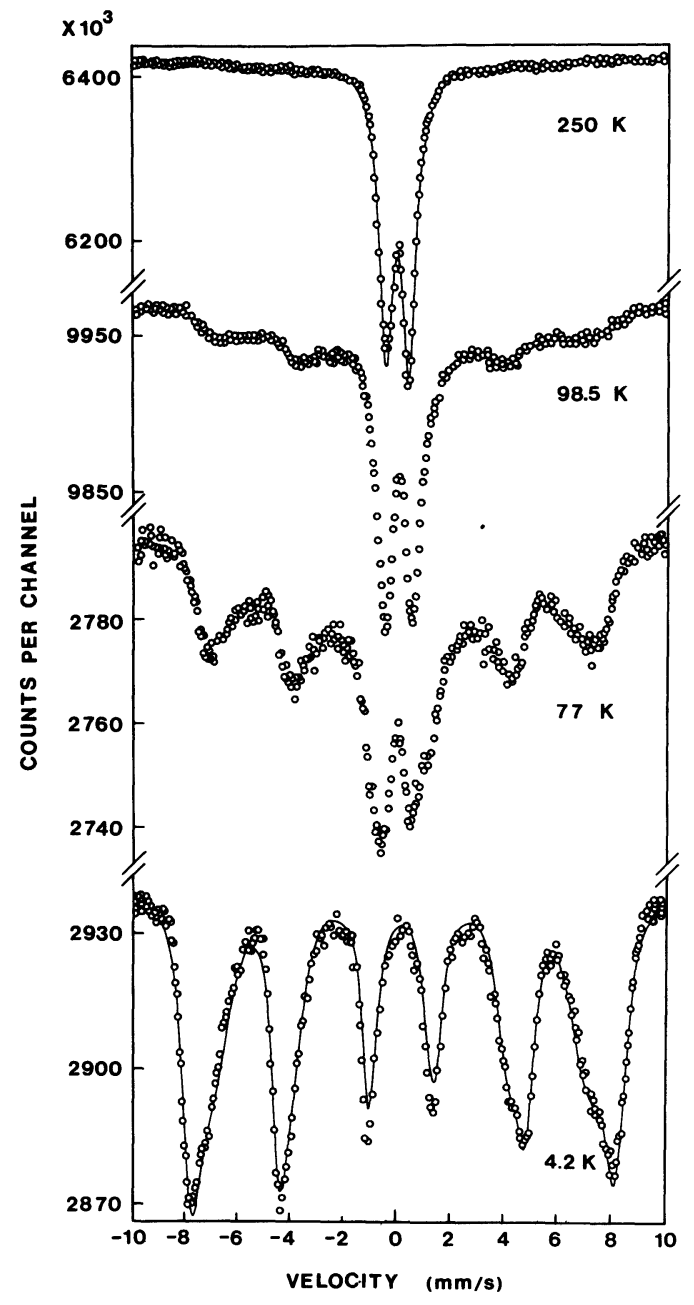

Fig. 5. - Temperature dependence of the Mössbauer spectra of sample $\mathrm{C}\left(\mathrm{Fe}_{2} \mathrm{O}_{3}\right)_{50}(\mathrm{BaO})_{35}\left(\mathrm{~B}_{2} \mathrm{O}_{3}\right)_{15}$.

Magnetization and susceptibility results for this sample $\mathrm{C}$ indicate a minor ferrimagnetic component (saturated at low field) and show a broad maximum of susceptibility at $70 \mathrm{~K}$. Remanence is observed below $70 \mathrm{~K}$ in a field of $18.8 \mathrm{kOe}$. The high temperature Curie-Weiss parameters are $C=4.31, \theta_{\mathrm{p}}=-194 \mathrm{~K}$ [20].

The Mössbauer spectra of sample D,

$$
\left(\mathrm{Fe}_{2} \mathrm{O}_{3}\right)_{5}(\mathrm{BaO})_{24}\left(\mathrm{~B}_{2} \mathrm{O}_{3}\right)_{71} \text {, }
$$

reveal in the temperature range from 300 to $4.2 \mathrm{~K}$ three lines which are decomposed into two symmetrical doublets characterizing the presence of $\mathrm{Fe}^{2+}$ $(\sim 12 \%)$ and $\mathrm{Fe}^{3+}(\sim 88 \%)$ valence states (Fig. 6, Table IV). At $1.5 \mathrm{~K}$, a broad magnetic spectrum coexists with the paramagnetic pattern. Isothermal magnetization is linear above $20 \mathrm{~K}$ up to fields of $20 \mathrm{kOe}$ and deviates from linearity at higher fields without reaching saturation at $150 \mathrm{kOe}$. The reciprocal susceptibility vs. temperature shows a CurieWeiss behaviour $\left(C=3.08, \theta_{\mathrm{p}}=-9 \mathrm{~K}\right)$ above $20 \mathrm{~K}$ and presents no singularity down to $1.5 \mathrm{~K}$.

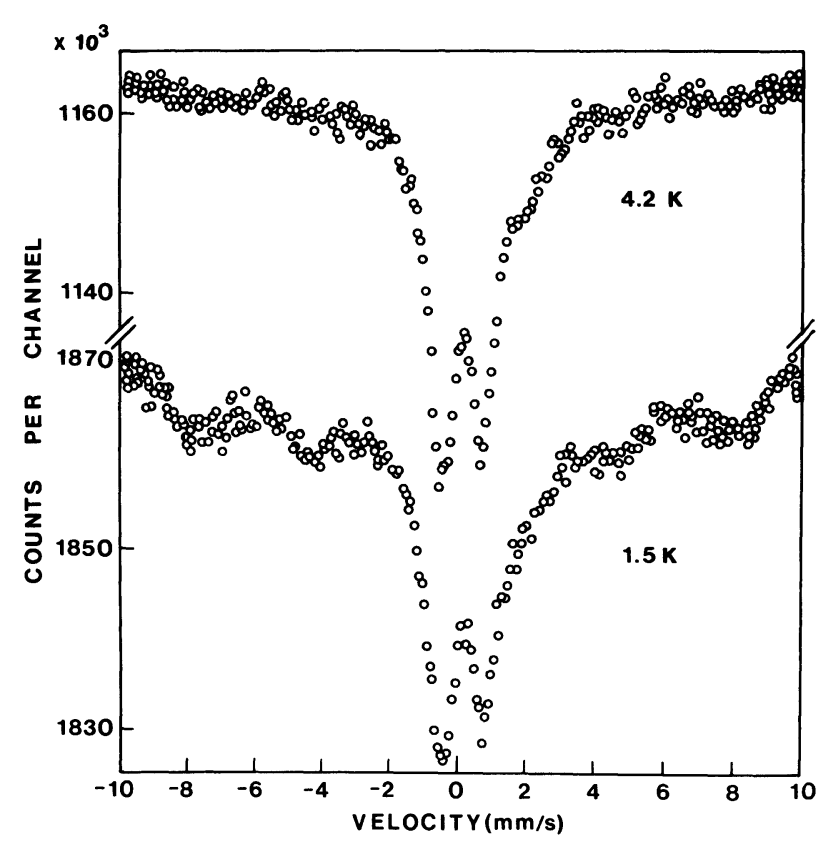

Fig. 6. - Mössbauer spectra at 4.2 and $1.5 \mathrm{~K}$ of sample $\mathrm{D}\left(\mathrm{Fe}_{2} \mathrm{O}_{3}\right)_{5}(\mathrm{BaO})_{24}\left(\mathrm{~B}_{2} \mathrm{O}_{3}\right)_{71}$.

Table IV. - Mössbauer parameters of $\left(\mathrm{Fe}_{2} \mathrm{O}_{3}\right)_{5}$ $(\mathrm{BaO})_{24}\left(\mathrm{~B}_{2} \mathrm{O}_{3}\right)_{71}$, sample $\mathrm{D}$, at $77 \mathrm{~K}$.

\begin{tabular}{|c|c|c|c|c|c|}
\hline$T(\mathrm{~K})$ & & $\begin{array}{c}\delta_{\mathrm{IS}}^{(\mathrm{mm} / \mathrm{s})} \\
\pm 0.02\end{array}$ & $\begin{array}{c}\Delta_{\mathrm{L}}^{(\mathrm{mm} / \mathrm{s})} \\
\pm 0.02\end{array}$ & $\begin{array}{c}\mathrm{W}_{\mathrm{L}}(\mathrm{mm} / \mathrm{s}) \\
\pm 0.02\end{array}$ & $\begin{array}{c}\text { relative } \\
\text { fraction } \\
\pm 3\end{array}$ \\
\hline 77 & $\mathrm{Pe}^{3+}$ & 0.41 & 1.15 & 0.67 & 88 \\
& $\mathrm{Pe}^{2+}$ & 0.97 & 2.74 & 0.59 & 12 \\
\hline
\end{tabular}

4. Analysis of hyperfine interaction distributions in the glasses $\mathrm{Fe}_{2} \mathrm{O}_{3}-\mathrm{BaO}-\mathrm{B}_{2} \mathrm{O}_{3}$. - The large linewidths observed in the Mössbauer spectra of amorphous materials arise from distribution of hyperfine interactions. The analysis of these distributions is useful for probing the local structure and for establishing the electronic and magnetic properties by reference, for instance, to computer modelling predictions of amorphous structures [1, 4]. Let us recall some general features of the ${ }^{57} \mathrm{Fe}$ resonance shapes in the presence of such distributions and introduce the computer analysis of the experimental results obtained in this work.

By reference to the systematics of isomer shifts $\left(\delta_{\mathrm{IS}}\right)$ in crystalline materials [26], the distribution of $\delta_{\text {IS }}$ will be small, in comparison to the resonance width, in the case of a single valence state, coordination number, and nature of ligands of the $\mathrm{Fe}$ atoms. On the contrary, differing $\delta_{\text {IS }}$ are associated with different valence states or coordination numbers and these will be correlated to their quadrupole and magnetic hyperfine interactions. A reliable analysis of distributions of hyperfine interactions from Mössbauer data will be possible only in the former situation of negligible $\delta_{\text {IS }}$ distribution. In other cases, some correlations between parameters have to be assumed. 
Assuming a unique value for $\delta_{\mathrm{IS}}$, the distribution function of the quadrupole splitting,

$$
\Delta=\frac{1}{2} e^{2} q Q\left(1+\frac{1}{3} \eta^{2}\right)^{1 / 2},
$$

can be directly deduced from paramagnetic data. It is noteworthy that quadrupole doublets will be symmetrical under the above assumption, whereas they will be asymmetric in the case of correlated distributions of $\delta_{\mathrm{IS}}$ and $\Delta[27]$.

In the presence of additional magnetic interaction and in the absence of single ion anisotropy (e.g. the ${ }^{6} \mathrm{~S}$ configuration of $\mathrm{Fe}^{3+}$ ) one does not expect any directional correlation between local anisotropy (i.e. electric field gradient, $E F G$ ) axes and hyperfine field axes. A perturbation treatment of the quadrupole interaction on a magnetic interaction predicts an apparent cancellation of quadrupole effect in the case of random orientation $(\theta)$ between $E F G$ and $H_{\text {hf }}$ axes. Indeed, the angular average of the quadrupole perturbation of the nuclear magnetic energy levels can be written to first order :

$$
\left\langle E_{\mathrm{Q}}\right\rangle=\left\langle\frac{1}{8} e^{2} q Q\left(3 \cos ^{2} \theta-1\right)\right\rangle=0 .
$$

(The same result is obtained for non-axial EFG tensor.)

This means that the barycentres of the six magnetic resonance components are arranged symmetrically with respect to the isomer shift. However numerical calculation of the spectral shape reveals that each of the six lines actually is asymmetric in the presence of a defined sign of $\Delta$ and when the asymmetry parameter $(\eta)$ is small (Fig. 7). Similar conclusions are reached from analytical calculations [28]. The detection of such spectral asymmetry should allow information

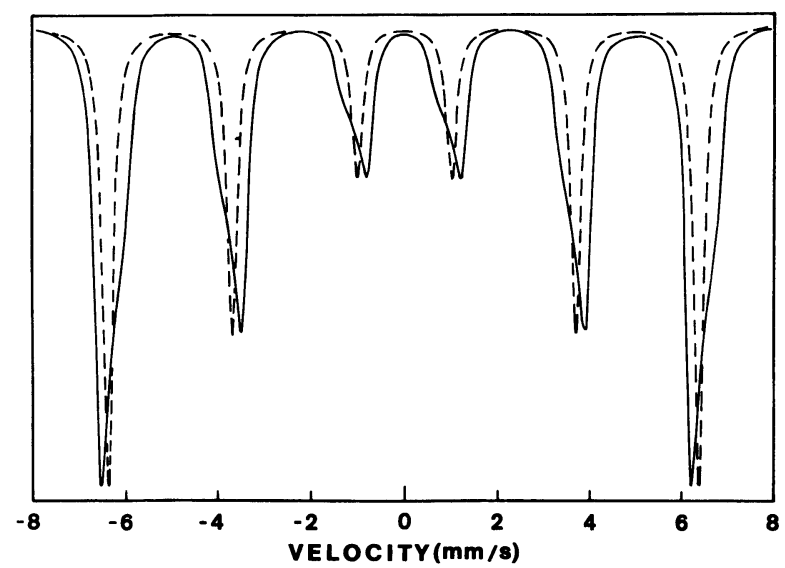

Fig. 7. - Simulated Mössbauer spectrum (full line) for a random orientation between $E F G$ and $H_{\mathrm{hf}}$ axes $(\bar{\Delta}=1 \mathrm{~mm} / \mathrm{s}$, $H_{\mathrm{hf}}=400 \mathrm{kOe}$, component width $: 0.25 \mathrm{~mm} / \mathrm{s}$ ). The dotted line represents the spectral shape in the absence of quadrupole interaction, in order to point out the lineshape asymmetry and the asymmetry in peak maxima energies corresponding to the above situation. These features will be washed out in an experimental situation via the inherent distributions in modulus of $\Delta$ and $H_{\mathrm{hf}}$. to be inferred concerning the sign of the principal component of the field gradient and/or the asymmetry parameter. In practice, such asymmetries will unfortunately be difficult to detect, owing to the relatively small field gradients acting at the nucleus of an Sstate ion $\left(\Delta\left(\mathrm{Fe}^{3+}\right)<1.5 \mathrm{~mm} / \mathrm{s}\right)$ and to the line broadening which will be induced by the concomitant $\Delta$ and $H_{\mathrm{hf}}$ distributions. The latter contributions were neglected in the lineshape calculation of figure 7 in order to illustrate the principal effect of the angular distribution alone.

In summary, the random distribution of $\theta$ provides to first order a symmetrical arrangement of the barycentres of the six resonance lines, each of these being equally broadened by a value $\Delta W_{\theta}$ estimated as [29] :

$$
\Delta W_{\theta}=2 \sqrt{\left\langle E_{\mathrm{Q}}^{2}\right\rangle}=\frac{1}{\sqrt{5}} \bar{\Delta}
$$

Adding an isomer shift distribution to the random angular distribution produces a uniform broadening if the two distributions are independent. If they are correlated, asymmetry is induced [27]. An additional distribution in the modulus of the quadrupole splitting gives rise to a broadening which will be equal for all the magnetic components. This contribution sums up to the above-mentioned angular distribution effect. The resulting linewidth can be calculated from the sum of second moments of the two distributions or more simply as :

$$
W=\sqrt{W_{\mathrm{L}}^{2}+\Delta W_{\theta}^{2}}
$$

where $W_{\mathrm{L}}$ is the linewidth observed in the paramagnetic phase.

An additional independent distribution of $H_{\mathrm{hf}}$ produces non-uniform line broadenings, in the ratio of the average transition energies of the components. Thus, unequal linewidths of the magnetic spectral components unequivocally characterize distribution in $H_{\mathrm{hf}}$.

The reliability of the analysis of combined distributions of hyperfine interactions is clearly limited and requires data of good statistical quality.

The hyperfine interaction distributions have been analysed numerically from the present experimental data according to the guidelines mentioned above. The Lorentzian component linewidth is constrained to an experimental value of $0.25 \mathrm{~mm} / \mathrm{s}$ (measured against a thin reference absorber under identical conditions) and spectral shapes are calculated by computer summation according to the relevant hyperfine interaction distribution. For sample $A$, the paramagnetic spectra $(42<T<670 \mathrm{~K})$ are very satisfactorily represented when it is assumed that there is constant isomer shift and a Gaussian distribution of the quadrupole splitting (Table I, Fig. 8). 


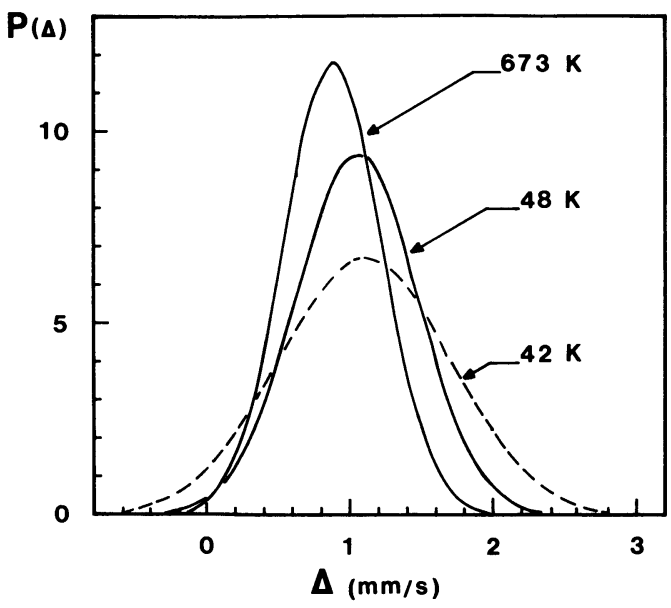

Fig. 8. - Temperature dependence and shape of the distribution of quadrupole splitting in sample A.

The broadening appearing at $42 \mathrm{~K}$ corresponds to the onset of magnetic hyperfine effects (Fig. 8).

The nearly symmetric magnetic spectra which are observed at $4.2 \mathrm{~K}$ are successfully analysed using the full Hamiltonians of nuclear interaction with : $a$ ) a constant isomer shift, $b$ ) the Gaussian distribution of quadrupole splitting obtained from the paramagnetic phase $(\eta=0), c)$ a spherical distribution for the polar angle $\theta$ between the $E F G$ and $H_{\mathrm{hf}}$ axes, d) a Gaussian distribution of $H_{\mathrm{hf}}, e$ ) no correlations between these distributions (Fig. 9, Table V). Figure 3 represents the data analysis by assuming equal weights for both signs of $\Delta$ and $\eta=0$. The quality of the fit is comparable when assuming one sign only for the $\Delta$ distribution. Thus, as already pointed out above, the sign of $\Delta$ as well as the magnitude of $\Delta$ cannot be reliably deduced from combined quadrupole and magnetic spectra because of the relatively small value of $\bar{\Delta}$.

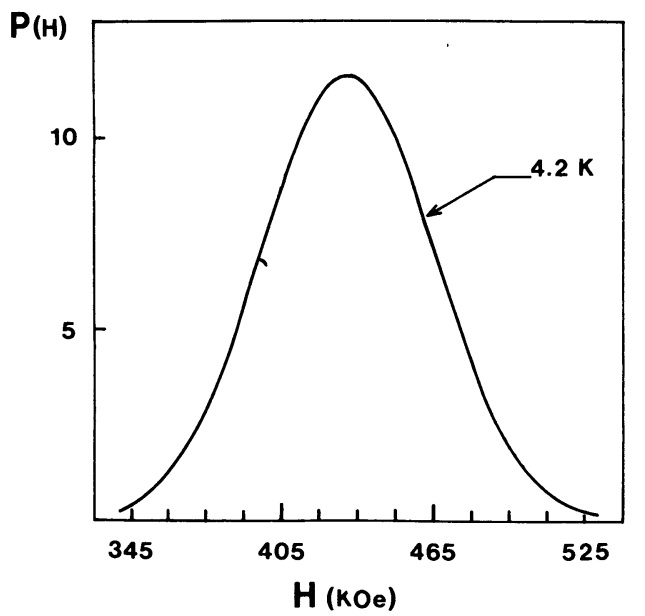

Fig. 9. - Deduced hyperfine field distribution at $4.2 \mathrm{~K}$ in sample A.
Table V. - Mössbauer parameters of $\left(\mathrm{Fe}_{2} \mathrm{O}_{3}\right)_{30^{-}}$ $(\mathrm{BaO})_{45}\left(\mathrm{~B}_{2} \mathrm{O}_{3}\right)_{25}$, sample $\mathrm{A}$, at $4.2 \mathrm{~K}$. Upper line from model a) assuming a Gaussian distribution of $\Delta$, a spherical distribution of $\theta$, an independent Gaussian distribution of $H_{\mathrm{hf}}$. Lower line from a simplified version of model a); the quadrupole splitting and angular distribution effects are taken into account via uniform broadening of the linewidths (see text). $\sigma_{\Delta}$ and $\sigma_{H}$ are the deviation of the Gaussian distribution of $\Delta$ and $\mathrm{H}_{\mathrm{hf}}$ respectively.

\begin{tabular}{|l|c|c|c|c|c|c|}
\hline$T(\mathrm{~K})$ & $\begin{array}{c}\delta_{\mathrm{IS}}(\mathrm{mm} / \mathrm{s}) \\
\pm 0.02\end{array}$ & $\begin{array}{c}W(\mathrm{~mm} / \mathrm{s}) \\
\pm 0.02\end{array}$ & $\begin{array}{c}\bar{\Delta}(\mathrm{mm} / \mathrm{s}) \\
\pm 0.02\end{array}$ & $\sigma_{\Delta}$ & $\begin{array}{c}\overline{\bar{H}}_{\mathrm{hf}}(\mathrm{kOOe}) \\
\pm 5\end{array}$ & $\begin{array}{c}\sigma_{\mathrm{H}} \\
\pm 0.5\end{array}$ \\
\hline 4.2 & 0.34 & 0.25 & $1.08^{*}$ & $0.3^{*}$ & 425 & 23 \\
& 0.36 & 0.8 & 0 & - & 431 & 19 \\
\hline
\end{tabular}

$(*)$ Fixed values.

In order to lift this ambiguity an experiment was performed under applied field at a temperature which is sufficiently high so that the susceptibility is negligible. The experimental spectrum obtained in a field of $100 \mathrm{kOe}$ at a temperature of $300 \mathrm{~K} \mathrm{[30]}$ is compared to computer simulations (Fig. 10). These have been performed by numerical integration in order to represent the random orientation between effective field at the nucleus and $E F G$ principal axis. The Gaussian distribution of $\Delta$ is included in the calculations $\left(\sigma_{\Delta}=0.30 \mathrm{~mm} / \mathrm{s}\right)$. The Lorentzian component width is $0.30 \mathrm{~mm} / \mathrm{s}$, i.e. slightly broadened owing to the fringing magnetic field occurring at the source. A numerical fit of experimental data to the above model is impracticable because of prohibitive computer time. However, a visual inspection of the calculated spectral shapes reveals that a spectral asymmetry unequivocally demonstrates a weighting in sign of the $\Delta$ distribution and a value of the $E F G$ asymmetry parameter $\eta$ differing significantly from unity (Fig. 10). The present experimental result (Fig. 10a) is adequately represented when assuming a positive sign only for the $\Delta$ distribution and $\eta=0.5$ (Fig. 10b). Nevertheless, spectral shape simulations illustrate clearly that the deduced weight of the + and - wings in the $\Delta$ distributions is strongy correlated with the value of $\eta$. For instance, an asymmetric distribution in sign of $\Delta$ and a value of $\eta$ differing from unity is certainly consistent with the measurement. Summarizing, it may be pointed out that the external field measurement in the paramagnetic amorphous phase demonstrates unequivocally a significant weighting to positive sign of the $\Delta$ distribution and a value of $\eta$ deviating from unity. This information cannot be extracted reliably from the magnetic hyperfine data in the speromagnetic phase. However, the external field method does not allow simultaneous analyses of the sign distributions of $\Delta$ and of the value of $\eta$. 


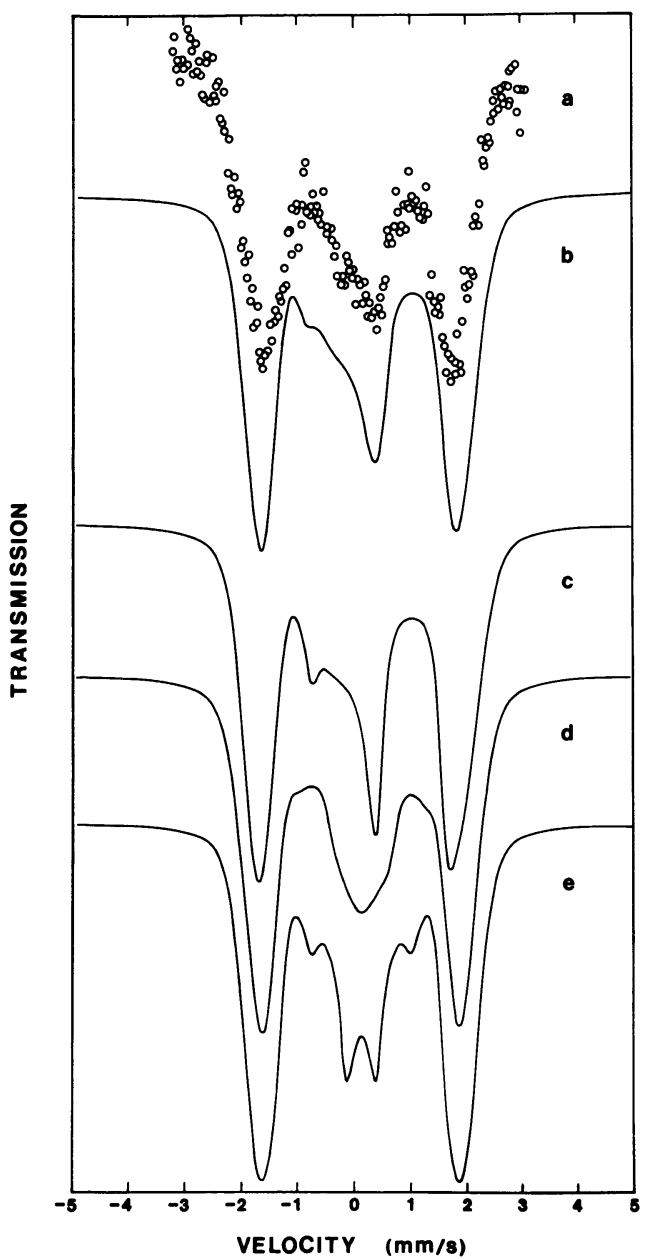

Fig. 10. - a) Mössbauer spectrum of sample A measured at $300 \mathrm{~K}$ in an external field of $100 \mathrm{kOe}$. The solid lines represent spectral lineshapes computed for a random orientation between the $E F G$ and effective field $(95 \mathrm{kOe})$ axes and for a Gaussian distribution of $\Delta(\bar{\Delta}=1.08 \mathrm{~mm} / \mathrm{s}$, $\sigma_{\Delta}=0.30 \mathrm{~mm} / \mathrm{s}$, Lorentzian width of $\left.\left.0.30 \mathrm{~mm} / \mathrm{s}\right) ; b\right) \Delta$ distribution of positive sign only, $\eta=0.5 ; c$ ) as in $b$ ), $\eta=0 ; d)$ as in $b), \eta=1 ; e$ ) equal weights of positive and negative signs of $\Delta, \eta=0$.

The experimental data obtained on the other three samples (B, C, D) have not been computer-analysed in detail since the isomer shift distribution revealed by the paramagnetic phase data renders a complete analysis prohibitive; in any case, a detailed understanding of the magnetic behaviour will be prevented by the additional complexity in the presence of distributions of valence states and coordination of the iron ions. This restriction applies both to local measurements, e.g., hyperfine interactions, and even to a larger extent to macroscopic results (magnetization and susceptibility measurements).

For sample B, the paramagnetic data

$$
(300 \mathrm{~K}>T>24 \mathrm{~K})
$$

reveal the occurrence of both $\mathrm{Fe}^{2+}$ and $\mathrm{Fe}^{3+}$ ions from the respective isomer shifts of the two doublets.
The QS distributions are well represented by broadened Lorentzian lines (Table II). The magnetic data at $4.2 \mathrm{~K}$ are satisfactorily fitted using a perturbation calculation (Eq. (2)) : the $\delta_{\text {IS }}$ difference between the two components was constrained to the value determined in the paramagnetic phase. For the $\mathrm{Fe}^{3+}$ component the effect of the quadrupole splitting distribution and of the random orientation of the $E F G$ and $H_{\mathrm{hr}}$ axes was introduced as a uniform line broadening (Eqs. (1) and (2)) (Table II). For the $\mathrm{Fe}^{2+}$ ions, owing to the single ion anisotropy, the $E F G$ and $H_{\mathrm{hr}}$ axes are strongly correlated; thus $\theta$ is expected to present a defined value contrary to $\mathrm{Fe}^{3+}$ ions.

A satisfactory fit is achieved (Fig. 4) even with a single $\mathrm{Fe}^{2+}$ magnetic component by letting the angle $\theta$ for this site as a free parameter (Table II). However, a wide distribution of $H_{\mathrm{hf}}$ would be expected for $\mathrm{Fe}^{2+}$ ions as a result of the sensitivity of this parameter to orbital effects. Because of the low intensity of this site and the lack of spectral resolution the fit is actually insensitive to such effects. Thus, we believe that the deduced standard deviation of the $\mathrm{Fe}^{3+}$ Gaussian $H_{\mathrm{hf}}$ distribution is reliable.

The decomposition of the paramagnetic data of the more concentrated sample $\mathrm{C}$ into two broadened symmetric quadrupole doublets establishes the occurrence of $\mathrm{Fe}^{3+}$ ions only; these are distributed among octahedral and tetrahedral coordination sites as shown by the $0.13 \mathrm{~mm} / \mathrm{s}$ difference in isomer shifts. Consistent with the paramagnetic data, the saturation magnetic data $(4.2 \mathrm{~K}$ ) are analysed (using the perturbation calculation (Eq. (2)), in terms of two magnetic subspectra with randomly distributed $E F G$ and $H_{\mathrm{hf}}$ axes. The average fields are $H_{\mathrm{hf}}\left(\mathrm{O}_{\mathrm{h}}\right)=500 \mathrm{kOe}$ and $H_{\mathrm{hf}}\left(\mathrm{T}_{\mathrm{d}}\right)=445 \mathrm{kOe}$ while the deviations of their Gaussian distributions are respectively 23 and $9.5 \mathrm{kOe}$ (Table III, Fig. 5). The values of the hyperfine fields further confirm the attribution of the subspectra to octahedral and tetrahedral coordination of $\mathrm{Fe}^{3+}$.

5. Magnetic transitions and orderings in the amorphous oxides $\mathrm{Fe}_{2} \mathrm{O}_{3}-\mathrm{BaO}-\mathrm{B}_{2} \mathrm{O}_{3}$. - Combining the present Mössbauer data with the published bulk magnetic results $[19,23]$, three types of magnetic behaviour can be identified, corresponding respectively to low - (sample D), intermediate - (samples A, B) and high - (sample C) concentration range of magnetic ions.

Sample A is most easily discussed since here the iron occurs in a single valence state $\left(\mathrm{Fe}^{3+}\right)$ and coordination (tetrahedral). Above $42 \mathrm{~K}$, the Mössbauer spectra reveal paramagnetic behaviour. Between 42 and $29 \mathrm{~K}$, relaxation effects are observed in terms of coexisting unresolved magnetic and central paramagnetic subspectra (Fig. 2), with the relative intensity of the latter decreasing as temperature is lowered. Below $29 \mathrm{~K}$, resolved magnetic spectra appear. Application of an external field up to $45 \mathrm{kOe}$ induces 
merely a line broadening both in the intermediate temperature range $(40-34 \mathrm{~K}$, Fig. 11$)$ and at $4.2 \mathrm{~K}$ (Fig. 3). In particular, at the latter temperature, no polarization of magnetization is induced since the relative areas of the spectral components are unaffected by the external field (Fig. 3).

Among the conceivable explanations for the measured temperature dependence, small particle superparamagnetism is definitely ruled out on the basis of the following arguments : electron microscopy (resolution : $\sim 50 \AA$ ) does not reveal small particles and magnetization data do not show the $\sigma$ vs. $H / T$ superposition behaviour, typical for non-interacting superparamagnetic particles $[20,23]$. In a true superparamagnet, the nearly saturated magnetic component should coexist in the Mössbauer spectrum with the paramagnetic doublet [31], contrary to experiment. Finally, in the temperature range from 35 to $45 \mathrm{~K}$, a large magnetic splitting would be predicted for small magnetic particles at an external field of $45 \mathrm{kOe}$, which is not observed (Fig. 11). Paramagnetic relaxation effects are ruled out because of the narrow temperature range of the smeared spectra and from the spectral shape evolution.

Magnetic ordering with a wide distribution in transition temperatures cannot account for the results since the components which would order at the higher temperature $(40 \mathrm{~K})$ should already be resolved at $35 \mathrm{~K}$. Distribution of molecular field from site to site according to the near neighbour atomic environment induces also significant line broadening in the vicinity of a homogeneous ordering temperature [32].

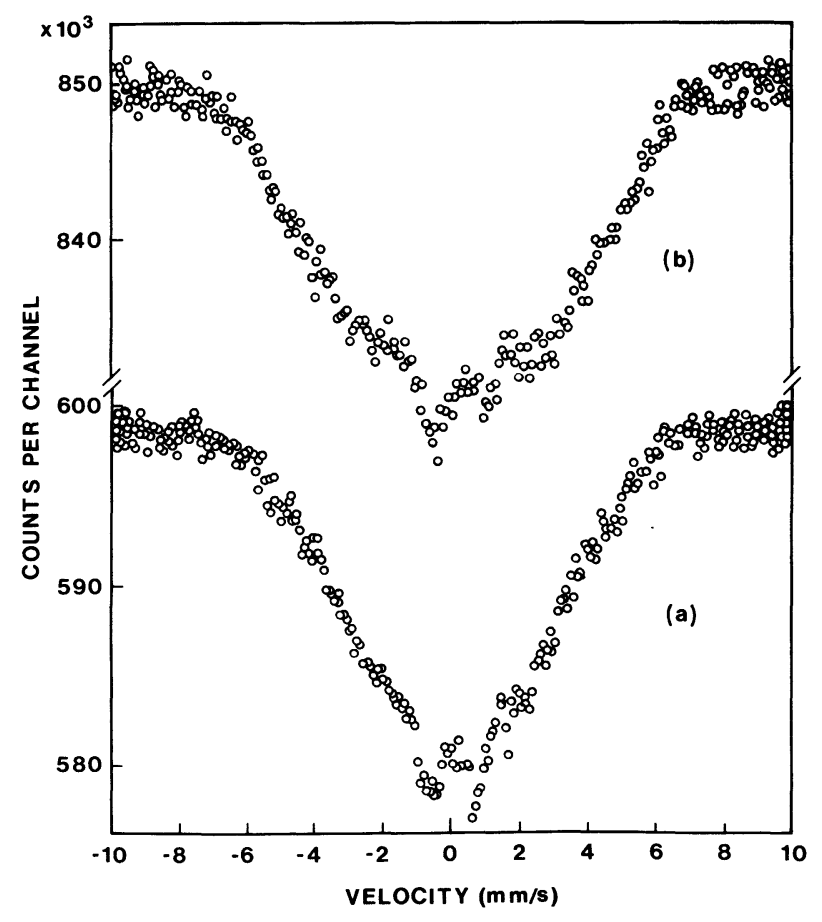

Fig. 11. - Mössbauer spectra of sample A measured at $35 \mathrm{~K}$ without (a) and with an external field of $45 \mathrm{kOe}(\mathrm{b})$.
However, in this model, the broadening should extend to reduced temperatures $T_{/} T_{\mathrm{c}}$ much lower than the experimentally observed value of 0.75 .

All the above cited Mössbauer results, along with the irreversible magnetization effects, the external field dependence of the dc susceptibility [23] and the ac susceptibility cusp characterize a mictomagnetic transition [25]. The temperature dependence of Mössbauer spectra between 40 and $30 \mathrm{~K}$ is very similar to that predicted from a model of spherical relaxation, with a relaxation rate decreasing at lower temperature [33, 34]. However, tentative fits with such a model show that a distribution of relaxation rates should be considered.

A spherical relaxation mechanism with a narrow distribution in relaxation rate (or freezing temperatures) has already been concluded from Mössbauer results in an established spin glass system : $\mathrm{Eu}_{1-x} \mathrm{Gd}_{x} \mathrm{~S}$ [35]. The mictomagnetic transition occurring in the present oxide glass is understood in terms of a progressive freezing of magnetic clusters arising from frustration effects, similar to the picture originally introduced by Tholence and Tournier [36]. Contrary to early assumptions [36], strong interactions couple the magnetic clusters via dipolar or (and) frustrated exchange interactions, as indicated by the negligible effect of the external field in the vicinity of the spin freezing temperature $\left(T_{\mathrm{f}}\right)$. The frequency dependence of $T_{\mathrm{f}}$, which is revealed by the difference between the ac susceptibility cusp and the Mössbauer transition temperature, further confirms a freezing mechanism with significant interactions among clusters. Such interactions between magnetic clusters have been repeatedly invoked to explain the peculiar properties of the mictomagnetic transition, in particular to account for the Fulcher law dependence of the relaxation rate in the vicinity of the spin freezing temperature [37-40].

Because of frustration effects, which are intrinsic to an amorphous solid with antiferromagnetic exchange, the magnetic structure is speromagnetic, i.e. random freezing of the spins [5] ; antiferromagnetic-like order extends at the most over a few interatomic distances. The speromagnetic structure at $4.2 \mathrm{~K}$ is revealed by the absence of any detectable polarization in an external field of $45 \mathrm{kOe}$. This type of order is already indicated by the very low induced magnetization ( $\sim 10^{-2}$ of saturation value) and by the absence of saturation up to $150 \mathrm{kOe}$.

The magnetic transitions occurring in the other glasses have been investigated in less detail, owing to the additional complexity introduced by the presence of several coordinations and valence states of the iron ions. The narrow temperature range of the transition observed in the Mössbauer spectra of sample B suggests a mictomagnetic transition similar to that reported for sample $A$. The simultaneous appearance of the magnetic hyperfine interaction at both $\mathrm{Fe}^{2+}$ and $\mathrm{Fe}^{3+}$ sites demonstrates homogeneous distri- 
bution of the two valence states within the amorphous solid.

The temperature dependence of the Mössbauer spectra at high concentration in magnetic ions (sample C) is suggestive of small particle superparamagnetism (Fig. 5). Indeed, one observes superposed paramagnetic and magnetic spectra over a wide temperature range $(60-200 \mathrm{~K})$ and the nearly saturated hyperfine field component appears already at high temperature. The observed temperature dependence is attributed to a progressive freezing of magnetization relaxation, with however much smaller interactions between clusters than in the intermediate concentration range (samples A, B). The latter conclusion contradicts the usual behaviour involving an increase of intercluster interactions with concentration of magnetic ions as found for instance in $\mathrm{Eu}_{x} \mathrm{Sr}_{1-x} \mathrm{~S}$ [39]. The observation is attributed to amorphous phase segregation in the present oxide glasses, i.e., the iron ions are no longer statistically distributed within the glass in sample C. Clusters of relatively high $\mathrm{Fe}$ concentration coexist with regions depleted in this element, so that the interaction among clusters becomes negligible. The broad distribution of relaxation rate (or cluster size) may be connected with the occurrence of both tetrahedral and octahedral coordinations of the $\mathrm{Fe}^{3+}$ ions, thus inducing more severe frustration effects than in sample $A$ for instance.

In the less concentrated sample (D), the appearance, at $1.5 \mathrm{~K}$, of a magnetically split component superimposed on the paramagnetic quadrupole doublet in the Mössbauer spectra is attributed to paramagnetic relaxation effects for some of the iron ions (Fig. 6). Measurements at $4.2 \mathrm{~K}$ in large external magnetic fields (up to $80 \mathrm{kOe}$ ) reveal a magnetic splitting for a fraction of the $\mathrm{Fe}^{3+}$ ions (Fig. 12). For one component, the field dependence follows a Brillouin behaviour $\left(\mu=5 \mu_{\mathrm{B}}\right)$ indicating that the outer lines correspond to isolated paramagnetic $\mathrm{Fe}^{3+}$ ions. Another fraction (the central part of the spectra) does not split at all and merely feels the external field. This component is attributed to antiferromagnetically coupled dimers. The intermediate spectral lines correspond to an effective field of approximately $280 \mathrm{kOe}$; these are tentatively attributed to antiferromagnetic coupled trimers [18].

The magnetic properties discussed above concern mainly the low temperature data. Little attention has been paid to the high temperature behaviour i.e. the strong reduction of the calculated Curie constant (or effective paramagnetic moment) when compared to the expected free ion value. For sample $A$, for example, $C=1.52$ while the $\mathrm{Fe}^{3+}$ free ion value amounts 4.38. Ferey et al. [16] explain the lowering of the Curie constant in amorphous $\mathrm{FeF}_{3}$ under the assumption of a spread in magnitude of the antiferromagnetic exchange interactions as a consequence of frustration effects. It is surprising that in other systems, e.g. the cobalt and manganese alumino-

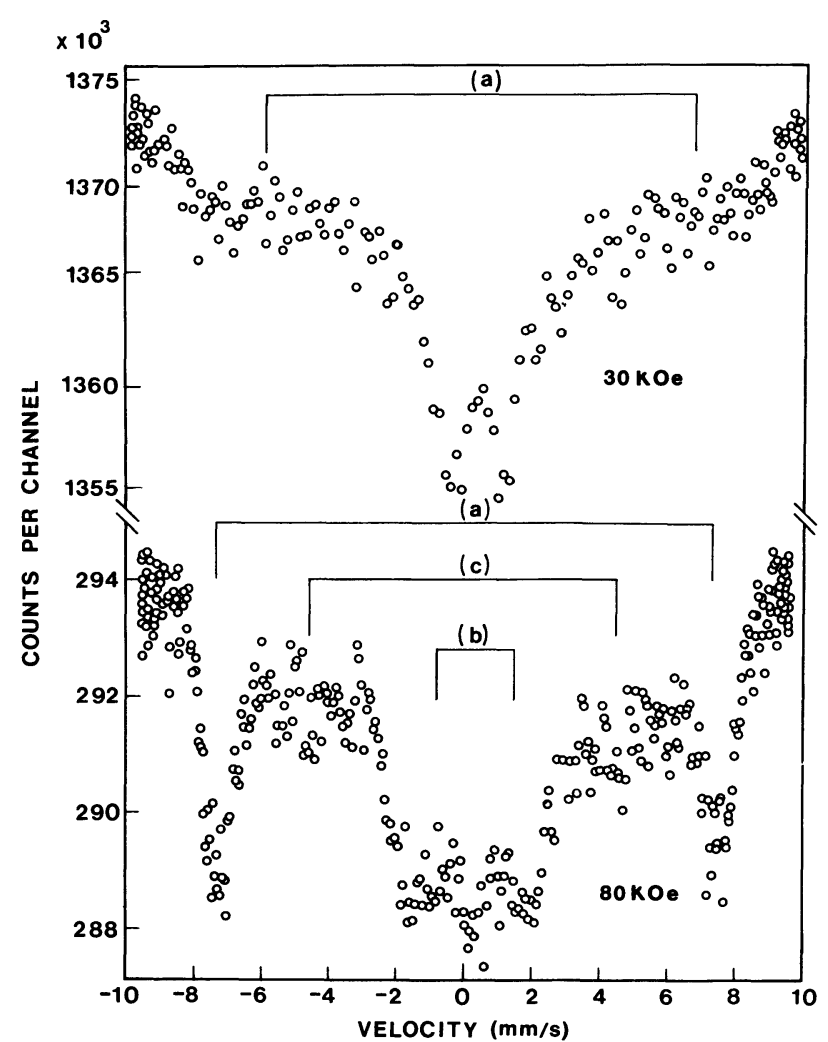

Fig. 12. - Mössbauer spectra of sample D measured at $4.2 \mathrm{~K}$ in external fields of 30 and $80 \mathrm{kOe}$. The bar diagram refers to the three subspectra corresponding to isolated (a), dimer (b) and other iron clusters (c).

silicate glasses, the paramagnetic Curie constants are found to be in agreement with the free ion values [41]. We suggest that the reduction of the Curie constant in the present systems arises from short-range antiferromagnetic coupling persisting up to temperatures much higher than the spin freezing temperature, so that some of the $\mathrm{Fe}^{3+}$ moments would not contribute to the Curie constant. A similar explanation has been already invoked to account for the magnetic behaviour of CuMn alloys [25] and of the $\mathrm{Fe}_{2} \mathrm{TiO}_{5}$ spin glass [42].

6. Electronic and structural properties of the amorphous oxides : $\mathrm{Fe}_{2} \mathrm{O}_{3}-\mathrm{BaO}-\mathrm{B}_{2} \mathrm{O}_{3}$. - By comparing the ${ }^{57} \mathrm{Fe}$ isomer shifts and average hyperfine fields data to those established in crystalline systems [26], it is concluded that sample A contains only $\mathrm{Fe}^{3+}\left({ }^{6} \mathrm{~S}\right)$ ions in tetrahedral coordination. It is of interest to notice that the phase initially crystallized from this sample $\left(\mathrm{BaFe}_{2} \mathrm{O}_{4}\right)$ similarly presents a tetrahedral $\mathrm{Fe}^{3+}$ coordination unit (See below Section 7). In samples $\mathrm{B}$ and $\mathrm{D}$, both $\mathrm{Fe}^{2+}\left({ }^{5} \mathrm{D}\right)$ and $\mathrm{Fe}^{3+}\left({ }^{6} \mathrm{~S}\right)$ valence states coexist. In sample $C$, one observes the $\mathrm{Fe}^{3+}$ valence state only, but in both octahedral and tetrahedral coordinations. The average iron to oxygen coordination number is definitely correlated with the atomic ratio of the elements present in the glass, in agreement with earlier conclusions [13].

The occurrence at low iron concentration (sample D) 
of small clusters (dimers, trimers) coexisting with isolated $\mathrm{Fe}^{3+}$ ions agrees with previous report [18]. This feature appears to be general for iron-based oxide glasses. The presence of such clusters in glasses with $\mathrm{Fe}_{2} \mathrm{O}_{3}$ concentration as low as 0.05 wt. \% has also been concluded from the concentration dependence of the linewidth of the $\mathrm{Fe}^{3+}$ EPR spectra in sodium silicate glasses [43]. At high iron concentration (sample $\mathrm{C}$ ), the non-random distribution of $\mathrm{Fe}$ ions revealed by the pseudo-superparamagnetic behaviour has already been claimed in other systems [17].

The distribution of quadrupole splitting, observed in all samples is attributed to fluctuations in bond distances and angles. The recent investigation of simple ionic insulating glasses $\left(\mathrm{a}-\mathrm{Y}_{3} \mathrm{Fe}_{5} \mathrm{O}_{12}\right.$ and $\mathrm{a}-\mathrm{FeF}_{3}$ ) has been complemented by computer modelling of their amorphous structure [4]. The computer models were constructed using a random packing of hard spheres (RPHS) with the additional requirement that ions of identical charge be separated as far as possible within the building algorithm [4]. Using a point charge model, this technique permits generation of histograms for the quadrupole splitting distributions [44]. An analytic form for these can be written as :

$$
P(\Delta)=\left(\Delta^{d-1} ; \sigma^{d}\right) \exp \left(-\Delta^{2} ; 2 \sigma^{2}\right)
$$

with $d=5$ for the RPHS model [44, 45]. These calculations consistently predict that the $\Delta$ distributions contain approximatively as many positive as negative values and that the marginal distribution, $P(\eta)$, of the asymmetry parameter increases with $\eta$. The function (Eq. (3)) with $d=2$, which takes into account some degree of short-range order has been successfully applied to amorphous $\mathrm{FeF}_{3}$ for instance [46]. For sample $A$, where the analysis of the $\Delta$ distribution is performed unequivocally, neither of the functions (Eq. (3)) with $d=2$ or $d=5$ provide an adequate description of the data. By contrast, a Gaussian distribution provides an excellent fit (Table I). This indicates more short-range order than in $\mathrm{a}-\mathrm{FeF}_{3}$. Also, our results establish significant asymmetry in the sign distribution of the $E F G$ principal component and deviation of $\eta$ from unity, in disagreement with the predictions from the above random models. It is to be noted that in most of the published works the sign of the EFG has not been determined. In summary, the present discrepancies with the RPHS model demonstrate a considerable degree of short-range order in our amorphous samples. It is concluded that their structure consists of a random packing of nearly constant structural units, with bonding angle and distance fluctuations around average values [46]. Comparable conclusions have been reached recently in other systems, i.e. amorphous alloys $\mathrm{Eu}_{80} \mathrm{Au}_{20}$ and $\mathrm{Gd}_{80} \mathrm{Au}_{20}$ [47].

The comparison of the electric field gradient data in glasses of different compositions and the tempe- rature dependence of this parameter represents potentially a result of interest for the elucidation of the structural and elastic properties. However, the present status of glass computer modelling and of computations of lattice contribution to field gradient does not allow this goal to be presently reached [4, 44]. Even in crystalline materials the number of results and calculations is very scarce [26].

7. Crystallization of the oxide glass : $\left(\mathrm{Fe}_{2} \mathrm{O}_{3}\right)_{30^{-}}$ $(\mathbf{B a O})_{45}-\left(\mathbf{B}_{2} \mathbf{O}_{3}\right)_{25} \cdot$ - The crystallization process has been followed by ${ }^{57} \mathrm{Fe}$ Mössbauer spectroscopy for sample A. Previous differential thermal analysis revealed a series of peaks at $790,840,880$ and $910 \mathrm{~K}$. Using X-ray and electron diffraction, these peaks were attributed respectively to the crystallization of $\mathrm{BaFe}_{2} \mathrm{O}_{4}$, crystallization of complex borates $(\mathrm{BaO}$, $\mathrm{B}_{2} \mathrm{O}_{3}$ ), crystallization of barium hexaferrite and final recombination of the borates $[19,20]$.

Two independent series of Mössbauer experiments have been performed : one at successive annealing temperatures in steps of $30^{\circ}$, each measurement requiring a duration of the order of $24 \mathrm{~h}$. The second at 4.2 and $77 \mathrm{~K}$, following successive thermal annealings at the same temperatures as above. The resulting spectral shapes are particularly complex and difficult to analyse reliably. This is not surprising when the complexity of the $\mathrm{BaO}-\mathrm{Fe}_{2} \mathrm{O}_{3}$ phase diagram is taken into consideration [48].

In the measurements performed at successive annealing temperatures up to $843 \mathrm{~K}$, a superposition of several quadrupole doublets was always observed; no significant anomaly in the Debye-Waller factor or in the resonance intensity is observed at any of the selected temperatures of measurement under present experimental conditions.

The phase analysis of the systems obtained on thermal annealing is best performed after quenching at low temperature, by comparing the Mössbauer spectra to those reported in the literature for the crystalline phases of the $\mathrm{BaO}-\mathrm{Fe}_{2} \mathrm{O}_{3}$ phase diagram [49, 50]. After annealing at $773 \mathrm{~K}$, the $4.2 \mathrm{~K}$ Mössbauer spectrum reveals the superposition of a new magnetic hyperfine spectrum $\left(H_{\mathrm{hf}}=462 \mathrm{kOe}\right)$ in addition to the magnetic spectrum of the amorphous phase (Fig. 13). This is attributed to a partial crystallization of $\mathrm{BaFe}_{2} \mathrm{O}_{4}$ coexisting with the original amorphous phase. However at a measurement temperature of $77 \mathrm{~K}$, no magnetic hyperfine spectrum is observed. Thus, the resulting $\mathrm{BaFe}_{2} \mathrm{O}_{4}$ crystals $\left(T_{\mathrm{N}}=880 \mathrm{~K}\right)$ exist as small particles and show superparamagnetic behaviour. After annealing at $803 \mathrm{~K}$, the amorphous component disappears and all the iron is in the form of superparamagnetic $\mathrm{BaFe}_{2} \mathrm{O}_{4}$ microcrystalline particles. After annealing at $823 \mathrm{~K}$, the spectrum measured at $4.2 \mathrm{~K}$ shows the superimposition of a central « paramagnetic » doublet and of the $\mathrm{BaFe}_{2} \mathrm{O}_{4}$ spectrum. At a measurement temperature of $77 \mathrm{~K}$, a magnetic component coexists 


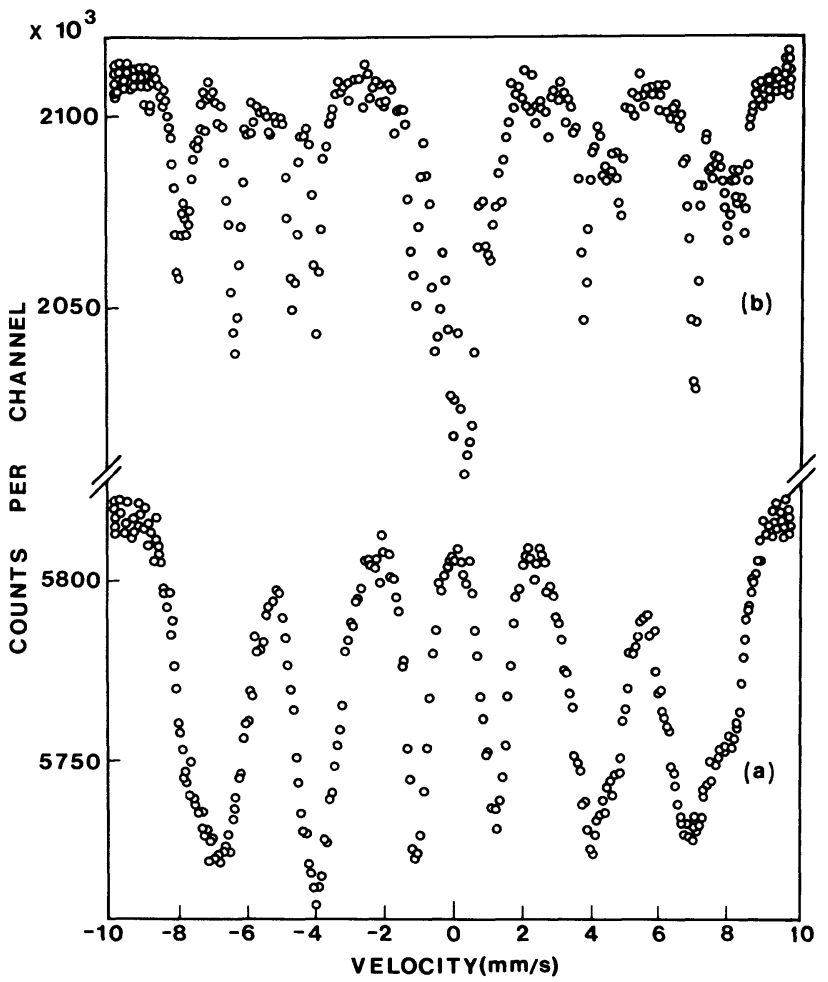

Fig. 13. - Mössbauer spectra measured after crystallization of sample $\mathrm{A}:$ a) measured at $4.2 \mathrm{~K}$ after annealing at $773 \mathrm{~K}$; b) measured at $300 \mathrm{~K}$, after annealing at $1053 \mathrm{~K}$.

with this doublet, thus demonstrating a growth of the $\mathrm{BaFe}_{2} \mathrm{O}_{4}$ particle size; the latter progressively lose their superparamagnetic character. The relative intensity of the new " paramagnetic » doublet measured at $4.2 \mathrm{~K}$ and $77 \mathrm{~K}$ increases upon thermal annealing at $853 \mathrm{~K}, 873 \mathrm{~K}$ and $1053 \mathrm{~K}$ at the expense of the $\mathrm{BaFe}_{2} \mathrm{O}_{4}$ spectrum. At this last annealing temperature, the formation of crystalline barium hexaferrite is clearly proven from the observation of three magnetic subspectra, typical for this phase at $300 \mathrm{~K}$ (Fig. 13). The observed behaviour is thus attributed to the progressive transformation upon annealing above $823 \mathrm{~K}$ of crystalline $\mathrm{BaFe}_{2} \mathrm{O}_{4}$ into $\mathrm{BaFe}_{12} \mathrm{O}_{19}$, which is first formed as small superparamagnetic particles whose size increases on further thermal annealing.

The present conclusion agrees with that suggested previously from X-ray and electron diffraction studies.

8. Conclusion. - The valence configuration and the structural environment of the magnetic ions $(\mathrm{Fe})$ present in the glasses $\mathrm{Fe}_{2} \mathrm{O}_{3}-\mathrm{BaO}-\mathrm{B}_{2} \mathrm{O}_{3}$ are identified from Mössbauer spectroscopy. The nature of the valence states $\left(\mathrm{Fe}^{2+}, \mathrm{Fe}^{3+}\right)$ is affected by preparative conditions while the average coordination is determined by the atomic ratio of the elements present in the glass.

The distribution of hyperfine parameters is discussed extensively for one sample in which the magnetic ions occur in single valence state and coordination. The quadrupole splitting $\Delta$ displays a Gaussian distribution function; in the magnetic state, the magnetic axis is at random with the $E F G$ axis, as expected for an S-state $\left(\mathrm{Fe}^{3+}\right)$ ion without single ion anisotropy. The hyperfine field also presents a distribution of Gaussian shape. The sign distribution of $\Delta$ should in principle be obtainable from the magnetic hyperfine data ; this procedure is unfortunately impracticable when considering the experimental precision and the intrinsically small values of $\Delta$. High temperature measurement under applied magnetic field unambiguously reveal the strong weighting to positive sign of the $\Delta$ distribution and a value of $\eta$ centred around 0.5 . The Gaussian distribution function of $\Delta$, the weighting in sign of the $\Delta$ distribution and the average value deduced for $\eta$ demonstrate significant short-range order, for instance, a defined tetrahedral coordination of the $\mathrm{Fe}^{3+}$ ions, with random fluctuations of bonding angles and distances. This is equivalent to the random coordination model. A random packing of spheres is totally ruled out in the present glasses.

Magnetic exchange is essentially antiferromagnetic in these glasses, as deduced from the large negative Curie-Weiss temperature. The structural disorder is responsible for the distribution in superexchange interactions ; therefore, the systems are highly frustrated from a magnetic point of view. A mictomagnetic transition is consistently established at intermediate $\mathrm{Fe}_{2} \mathrm{O}_{3}$ concentration $(30 \%)$ from Mössbauer results, irreversible remanence and a cusp in dynamic susceptibility. This transition is understood in terms of a progressive freezing of strongly interacting magnetic clusters. Consistent with frustration, the low temperature magnetic structure is speromagnetic, i.e. random freezing of the spins. However, the range of antiferromagnetic order cannot be fully specified in absence of neutron spectroscopy data. At small $(5 \%) \mathrm{Fe}_{2} \mathrm{O}_{3}$ concentration, the glass does not order down to $1.5 \mathrm{~K}$; however, local moments measured in an external field reveal the coexistence of isolated ions along with clusters on the atomic scale (dimers, trimers, etc.). At large $\mathrm{Fe}_{2} \mathrm{O}_{3}$ concentration $(50 \%)$, the system shows a quasi-superparamagnetic behaviour. This is attributed to heterogeneity of the iron distribution within the glass; therefore, the mictomagnetic transition corresponds to the freezing of clusters with weak interactions between them, thus showing up over a wide temperature range in Mössbauer spectroscopy.

The crystallization of the glasses proceeds in a complex sequence. The successive formation of barium ferrites up to the hexaferrite is revealed by Mössbauer spectroscopy, consistent with diffraction results. These phases form first as small particles (revealed by their superparamagnetic characteristics) and subsequently evolve in size.

Acknowledgments. - We thank $H$. Laville and J. C. Bernier for providing the samples used in this work and for helpful discussions. 


\section{References}

[1] Gaskell, P. H., J. Non-Cryst. Solids 32 (1979) 207 and J. Phys. C 12 (1979) 4337.

[2] Amorphous Magnetism I, ed. H. O. Hooper and A. M. de Graff (Plenum Press, New York) 1973.

[3] Amorphous Magnetism II, ed. R. A. Levy and R. Hasegawa (Plenum Press, New York) 1977.

[4] Lines, M. E., Phys. Rev. B 20 (1979) 3729; ibid B 21 (1980) 5793.

[5] Coey, J. M. D., J. Appl. Phys. 49 (1978) 1646.

[6] Ferre, J., Pommier, J., Renard, J. P., Knorr, K., J. Phys. C 13 (1980) 3697.

[7] Nägele, W., Knorr, K., Prandl, W., Convert, P., Buevoz, J. L., J. Phys. C 11 (1978) 3295.

[8] Verhelst, R. A., Kline, R. W., De Graff, A. M., HoOPer, H. O., Phys. Rev. B 11 (1975) 4427.

[9] Van Diepen, A. M., Popma, Th. J. A., J. Physique Colloq. 37 (1976) C6-755.

[10] Heiman, N., Kazama, N. S., J. Appl. Phys. 50 (1979) 7633.

Marusak, L. A., Messier, R., J. Appl. Phys. 50 (1979) 7630.

[11] Nishida, T., Takashima, Y., J. Non-Cryst. Solids 37 (1980) 37

[12] Raman, T., Rao, G. N., Chakravorty, D., J. NonCryst. Solids 29 (1978) 85.

[13] Syono, Y., Ito, A., Horie, O., J. Phys. Soc. Japan 46 (1979) 793.

[14] Bray, P. J., O’Keefe, J. G., Phys. Chem. Glasses 4 (1963) 37.

[15] Litterst, F. J., Tejada, J., Kalvius, G. M., J. Appl. Phys. 50 (1979) 7636.

[16] Ferey, G., Varret, F., Coey, J. M. D., J. Phys. C 12 (1979) L-531.

[17] Bukrey, R. R., Kenealy, P. F., Beard, G. B., HooPER, H. O., Phys. Rev. B 9 (1974) 1052.

[18] Moon, D. W., Aitken, J. M., McCrone, R. K., CieloszyK, G. S., Phys. Chem. Glasses 16 (1975) 91.

[19] Laville, H., Bernier, J. C., J. Mat. Sci. 15 (1980) 73.

[20] Laville, H., Thesis, Strasbourg (1980) unpublished.

[21] Shenoy, G. K., Friedt, J. M., Maletta, H., Ruby, S. L., Mössbauer Effect Methodology, Vol. 9, ed. I. J. Gruverman, C. W. Seidel and D. K. Dieterly (Plenum Publishing Company, New York) 1975 , p. 277.

[22] The collaboration of P. Beauvillain and J. P. Renard in performing the ac-susceptibility measurements on sample A is gratefully acknowledged.

[23] Laville, H., Friedt, J. M., Bernier, J. C., HassaNIAN, N., Revue Phys. Appl. 15 (1980) 1133.

[24] Chaumont, C., Private communication.

[25] BECK, P. A., Liquid and Amorphous Metals, ed. E. Lüscher, H. Coufal (Sijthoff and Noordhoff,
Alphen Van der Rijn, Holland) 1980, p. 545; Prog. Mat. Sci. 23 (1978) 1.

[26] Greenwood, N. N., GibB, T. C., Mössbauer Spectroscopy (Chapman and Hall, London) 1971.

[27] Chien, C. L., Hyp. Int. 4 (1978) 869.

[28] Le Caer, G., Dubois, J. M., Phys. Status Solidi a 64 (1981) 275 ; J. Phys. E 12 (1979) 1083

[29] Hang Nam OK, Morrish, A. H., Phys. Rev. B 22 (1980) 4215.

[30] This Mössbauer spectrum was recorded at the SNCI, Grenoble. We thank J. Chappert for his collaboration.

[31] Morup, S., Dumesic, J. A., Topsoe, H., Applications of Mössbauer Spectroscopy, Vol. 2, ed. R. L. Cohen (Academic Press, New York) 1980, p. 1.

[32] Coey, J. M. D., Sawatzky, G. A., Phys. Status Solidi b 44 (1971) 673.

[33] Dattagupta, S., Blume, M., Phys. Rev. B 10 (1974) 4540.

[34] Manykin, E. A., Onishchenko, E. V., Sov. Phys. Solid State 18 (1976) 1870.

[35] Litterst, F. J., Friedt, J. M., Tholence, J. L., Holtzberg, F., J. Phys. C 15 (1982) 1049.

[36] Tholence, J. L., Tournier, R., J. Physique Colloq. 35 (1974) C4-229.

[37] Meert, A. T., Wenger, L. E., J. Magn. Magn. Mater. 23 (1981) 165.

[38] Tholence, J. L., Solid State Commun. 35 (1980) 113.

[39] Maletta, H., J. Magn. Magn. Mater. 24 (1981) 179.

[40] Shtrikman, S., Wohlfarth, E. P., Phys. Lett. 85A (1981) 467.

[41] Morgownik, A. F. J., Mydosh, J. A., Wenger, L. E., J. Appl. Phys. 53 (1982) 2211.

[42] Atzmony, U., Gurewitz, E., Melamud, M., Pinto, H., Shaked, H., Gorodetsky, G., Wanklyn, B., Phys. Rev. Lett. 43 (1979) 782.

[43] Bogomolova, L. D., Henner, E. K., J. Magn. Reson. 41 (1980) 422.

[44] Eibschütz, M., Lines, M. E., VAN Uitert, L. G., GugGenheim, H. J., Zydik, G. J., Phys. Rev. B 24 (1981) 2343.

[45] Czjzex, G., Fink, J., Götz, F., Schmitt, H., Coey, J. M. D., Rebouillat, J. P., Lienard, A., Phys. Rev. B 23 (1981) 2513.

[46] Czjzek, G., Phys. Rev. B 25 (1982) 4908.

[47] Friedt, J. M., Maurer, M., Sanchez, J. P., Durand, J., J. Phys. F 12 (1982) 821.

[48] Kantor, P., Revcolevschi, A., Collongues, R. J., J. Mat. Sci. 8 (1973) 1359.

[49] Do-Dinh, C., Bertaut, E. F., Chappert, J., J. Physique 30 (1969) 566.

[50] Kreber, E., Gonser, U., Appl. Phys. 10 (1976) 175. 